\title{
[REVISED VERSION]
}

Article Title:

Teaching students to write about art: results of a four-year patchwork text project

Author names and affiliation:

Dr Craig Staff and Robert Farmer

The University of Northampton

Author addresses:

The University of Northampton

University Drive

Northampton

$\mathrm{NN} 15 \mathrm{PH}$

\section{Author biographies:}

Dr Craig Staff is currently Reader in Fine Art at the University of Northampton where he has worked since 2003, having completed his PhD in Fine Art (Painting) at Nottingham Trent University and his MFA (Distinction) at the University of Ulster. As well as having published on the intellectual histories of modernism, the broad focus of his recent research has considered how time is written into the work of art. His study Retroactivity and Contemporary Art, published last year by Bloomsbury considers contemporary art's relationship with both history and historical materials. His next monograph, forthcoming on Intellect, seeks to examine the notion, following Jean-Francois Lyotard, that paintings function as 'sites of time.'

Robert Farmer is the Learning Technology Manager at the University of Northampton, where he supports the Head of Learning Technology to lead and manage the University's award-winning Learning Technology Team. He previously worked at the University as a Learning Designer, Learning Technologist, and Learning Development Tutor, and prior to this was a full-time FE/HE lecturer, teaching and leading courses in philosophy, critical thinking, and digital filmmaking. His current research interests and publications include work on Socratic Dialogue in the Nelson-Heckmann tradition, the flipped classroom, blended and active learning, course and module design, patchwork text assessment, and educational videos.

\section{Abstract:}

This paper presents the findings from a four-year project designed to gather undergraduate Fine Art students' perceptions of replacing an essay with a Patchwork Text Assessment (PTA), a form of assessment in which a series of self-contained, thematically related patches are written at regular intervals over a series of weeks or months and are then stitched together with a final meta-patch exploring the unity and inter-relatedness of the individual patches. On completion of the PTA, students 
were asked a series of questions about their experiences, and analysis of their responses showed that they had found completing the PTA more difficult, more enjoyable, and more rewarding than writing an essay. Importantly, there were no suggestions that the PTA had dumbed down assessment practices, nor was there an increase in the workload of the academic staff supporting and assessing the PTA.

Keywords:

Patchwork Text, Assessment, Fine Art, Academic Writing, Higher Education

Total word count including references:

6,916 words [original version $=5,363$ words]

\section{Introduction}

The purpose of this paper is to present the findings of a four-year project designed to gather undergraduate Fine Art students' perceptions of Patchwork Text Assessment (PTA). At the beginning of the 2013/14 academic year, a 2,000 word essay in two level five Fine Art modules and a 1,500 word essay in a level four module were each replaced with a PTA. The 2,000 word PTA comprised eight entries of 250 words each. The 1,500 word PTA comprised 7 entries, each approximately 200 words in length. In all cases the learning outcomes being assessed remained the same, as did the final summative deadline (individual entries were fully editable until the final deadline). The inspiration for changing from an essay to a PTA was Richard Winter's article in the Guardian, 'Alternative to the essay', (Winter 2003a) in which five problems with conventional essays were outlined, and the PTA was proposed as a viable alternative which dealt with some of these problems. Initially designed as a one-year project, in order to determine that the broadly positive feedback gathered during the first year of the project was not atypical, the project was extended for a further three years.

\section{Literature Review}

Often Fine Art students are not accustomed to writing critically about art and its related contexts and discourses. As a result, they will often confer onto the written component of their degree programme a level of anxiety and intellectual estrangement. In one sense, this anxiety is bound up with an assumption that they are unable to acquire the necessary skills which conform to an 'essayist literacy.' (Lillis 2001: 53).

Equally, students within this pedagogical context can be dismissive of the place and role of writing within what is primarily a 'hands-on' subject; an attitude which is premised on the idea that they are enrolled on their programme of study primarily to make (rather than write about what they make) (Borg 2012: 5-6). This is often symptomatic of a more deeply held set of beliefs that see 'theory' and 'practice' as 
mutually exclusive categories. Although the provenance of this binary in one sense stems from the fact that historically Fine Art tutors were not suitably qualified to teach the art theory/art history strands of the curriculum, resulting in art history/cultural studies tutors being tasked with delivering this content (Wilson 2012: 41; Lockheart, et al. 2004: 94), a set of distinctions remain prevalent between what takes place within the context of the student's studio and their writing tasks.

According to Mayfield (2005), whereas making often entails knowledge that is tacit within a student-centered environment and is premised upon a shared experience, writing, essentially an 'academic' undertaking, entails the acquisition of knowledge through learning that is both tutor centered or oriented and can often be, for the learner, an isolated experience (Mayfield 2005: 2007). This is something that, according to Lockheart, et al., (2004) requires the learner to engage in what are fundamentally different 'modes' of learning, wherein,

students tend to develop practical skills in studio by doing - a kinetic mode - in contrast to the learning of writing skills - a much more static and linear mode. These modes require the adoption of completely different and diverse learning styles, which some students find impossible to negotiate. Moreover, the activities of research, reflection and analysis that are part of studio work may not be balanced with the research and linear analysis that is required of formal writing. (Lockheart, et al. 2004: 94).

In one sense, the introduction of the PTA format into what had been previously a more standard academic format of assessment reflects a broader tendency within HEIs across the UK to devise strategies that not only engage the learner with the theoretical component of their studies, but also helps them to learn. (Lockheart, et al. 2004: 95).

A PTA is a written assignment in which a series of self-contained, thematically related patches are written at fairly regular intervals over a series of weeks or months. The patches are then stitched together with a final meta-patch designed to highlight and explore the unity and inter-relatedness of the individual patches through a process of analysis, evaluation and reflection. Winter (2003b: 112) describes PTA follows:

The essence of a patchwork is that it consists of a variety of small sections, each of which is complete in itself, and that the overall unity of these component sections, although planned in advance, is finalized retrospectively, when they are 'stitched together'. Thus, a 'patchwork text' assignment is one that is gradually assembled during the course of a phase of teaching and consists of a sequence of fairly short pieces of writing, which are designed to be as varied as possible and to cover the educational objectives of the teaching. ... At the end of the course, 
students add a reflexive commentary to the short pieces they have already written, which they may also, if they wish, revise and edit.

The final reflexive entry, or meta-patch, that stitches together the individual patches is essential for the PTA, and in many ways this is what distinguishes it from an assessed portfolio. This is because a PTA is not simply a collection of items in which the reader or assessor is left to discern the ways in which the items are related; rather it is what Winter (2003b: 119) refers to as a pattern, and one which has a unity and a meaning which has been articulated by the students. Thus the reader of the PTA can see from the individual patches that the students have grappled with a wide range of the course material, and can see from the final entry that they have explored the inter-relations between the patches and have interpreted "what this course material 'means', to them, now' (Winter 2003b: 119).

Winter (2003b: 112-122) is critical of assessment practices in Higher Education in general, and of the overuse or inappropriate use of the essay as an assessment instrument in particular. He identifies five specific problems with the essay, including that it disenfranchises some students (particularly non-traditional students), that it promotes last-minute panic and poor attendance, and that it does not allow struggling students to be easily identified (Winter 2003a). However, the most interesting of Winter's criticisms of the essay is that it asks students to adopt a fundamentally unrealistic stance in terms of their relationship to knowledge. The essay, in the modern sense of the word, is usually considered to be a lengthy text in which the author offers an authoritative and well-reasoned argument or viewpoint on a subject about which they are an expert. However, students are not subject matter experts and it is not helpful to use assessment instruments that pretend otherwise. The strength of the PTA is that it reflects the real situation in which students find themselves, one where they are beginning to grapple with new ideas, to make sense of them and to integrate them with what they know already. Essentially, a PTA can be a much more appropriate type of assessment than the essay because it accurately represents the,

provisional and incomplete nature of learning ... [and recognises that students] are trying to come to terms with a variety of new and unfamiliar voices, in the midst of which they must try somehow to keep track of their own voice, as a participant but not (yet) as 'the master' (Winter 2003b: 121).

\section{Research Method}

The first stage of this project involved changing one of two summative assessments in three undergraduate modules (one at level four, two at level five) from what was either a 1,500 or 2,000 word essay to a PTA, although the term 'PTA' was not explicitly used with students; rather, it was referred to as an academic blog or journal. In the case of the 2,000 word PTA, students were required to write a total of 
eight 250 word entries. The first seven entries were based on a particular week's topic, and students were required to use the final journal entry to reflect upon the previous seven and the content of the entries as a whole. The entries were completed over the course of the first term, and the final deadline was in the first week of January. The learning outcomes being assessed remained the same as were used when assessing the original essay, and all deadlines, apart from the final one, were formative: however, it was explained to students that 'formative' was not a synonym for 'optional'. Formative feedback was given individually to students who had completed their third entry by the specified deadline, and students understood that they could revise earlier entries right up to the final deadline. Winter's requirement (2003b: 112) that PTA entries be shared with other students was not adopted, and the individual entries were kept private and accessible only to the individual students and their lecturer.

Students were invited to give their responses to the PTA approximately two weeks after receiving grades and feedback for the PTA, via an online questionnaire which contained a number of fixed response questions and a single free-text field for further comments. Students were asked to rate a series of statements about the PTA against a five point 'strongly agree' to 'strongly disagree' likert scale. Statements included, 'I liked being able to build up the writing slowly over a series of blog/journal entries, rather than writing the whole assignment at the end' and, 'I thought that this blog/journal assignment made the writing process easier and more manageable.' Other likert questions included statements about the functionality of the blog/journal tool, whether they would be happy to complete other assignments and whether they recommended that staff carry on using PTA (see tables 3, 4, and 5 below for the full list of questions and responses). Students were also asked what grade they had received and whether they thought that their grade was better or worse than the grades they normally received for written assessments. Finally, students were invited to submit a free text response in which they were encouraged to say whatever they wanted about their experiences with PTA.

In order to ensure that this research project met appropriate ethical standards for educational research, all survey responses were anonymous, all survey questions were optional, and no personal information that could be used to identify individual students was asked for. In addition, the nature of the research being undertaken was explained to all eligible participants, as was the fact that participation was entirely voluntary. BERA guidelines (BERA 2011) were closely adhered to during all of the project, but as the project progressed beyond its second year and started to become a more substantial research project, formal ethical approval was sought and granted.

\section{Findings}

\subsection{Quantitative Findings}


The survey population was defined as those students who: (i) were studying during any one of the four academic years over which the project was run, and; (ii) were taking one of the three fine art theory undergraduate modules (referred to as modules A, B and C) in which an essay had been replaced with a PTA. As can be seen from tables 1 and 2, the survey population comprised 398 students, of whom a total of ninety-two responded to the quantitative questions and of those ninety two, sixty also responded to the qualitative questions. However, it is important to note that while the total figures within each academic year do refer to unique individuals, the final total does not necessarily identify 398 unique individuals. This is because module $\mathrm{A}$ is a first year module, and modules $\mathrm{B}$ and $\mathrm{C}$ are second year modules; thus a student taking module $\mathrm{A}$ in 13/14 may subsequently have taken module $\mathrm{B}$ or $\mathrm{C}$ (but not $B$ and C) in $14 / 15$, and so on.

\begin{tabular}{|l|c|c|c|c|c|}
\hline & $2013 / 14$ & $2014 / 15$ & $2015 / 16$ & $2016 / 17$ & Total \\
\hline Module A & 87 & 36 & 54 & 43 & 220 \\
\hline Module B & 27 & 15 & 11 & 24 & 77 \\
\hline Module C & 33 & 29 & 21 & 18 & 101 \\
\hline Total & 147 & 80 & 86 & 85 & 398 \\
\hline
\end{tabular}

Table 1: Survey population

\begin{tabular}{|l|c|c|c|c|c|}
\hline & $2013 / 14$ & $2014 / 15$ & $2015 / 16$ & $2016 / 17$ & Total \\
\hline Quantitative responses & $34(23 \%)$ & $24(30 \%)$ & $19(22 \%)$ & $15(18 \%)$ & $92(23 \%)$ \\
\hline Qualitative responses & $23(16 \%)$ & $18(23 \%)$ & $14(16 \%)$ & $5(6 \%)$ & $60(15 \%)$ \\
\hline
\end{tabular}

Table 2: Survey responses and response rates (in brackets)

Responses to the quantitative questions are presented below, in tables 3, 4 and 5 .

\begin{tabular}{|l|c|c|c|c|c|}
\hline & $\begin{array}{c}\text { Agree } \\
\text { strongly }\end{array}$ & $\begin{array}{c}\text { Agree } \\
\text { slightly }\end{array}$ & $\begin{array}{c}\text { Neither } \\
\text { agree nor } \\
\text { disagree }\end{array}$ & $\begin{array}{c}\text { Disagree } \\
\text { slightly }\end{array}$ & $\begin{array}{c}\text { Disagree } \\
\text { strongly }\end{array}$ \\
\hline $\begin{array}{l}\text { 1. I liked being able to build up } \\
\text { the writing slowly over a series } \\
\text { of blog/journal entries, rather } \\
\text { than writing the whole } \\
\text { assignment at the end. }\end{array}$ & 51 & 21 & 8 & 9 & 3 \\
\hline $\begin{array}{l}\text { 2. I thought that this } \\
\text { blog/journal assignment made } \\
\text { the writing process easier and }\end{array}$ & 49 & 25 & 3 & 11 & 4 \\
\hline
\end{tabular}




\begin{tabular}{|c|c|c|c|c|c|}
\hline more manageable. & & & & & \\
\hline $\begin{array}{l}\text { 3. I learned a lot from } \\
\text { completing the assignment. }\end{array}$ & 54 & 23 & 8 & 6 & 1 \\
\hline $\begin{array}{l}\text { 4. I was pleased with the work } \\
\text { that I produced. }\end{array}$ & 34 & 36 & 14 & 4 & 3 \\
\hline $\begin{array}{l}\text { 5. I feel confident writing in an } \\
\text { academic style. }\end{array}$ & 18 & 38 & 18 & 10 & 8 \\
\hline $\begin{array}{l}\text { 6. I know where to get help } \\
\text { with my academic work if I } \\
\text { need it. }\end{array}$ & 51 & 28 & 8 & 1 & 2 \\
\hline $\begin{array}{l}\text { 7. I feel more confident doing } \\
\text { this type of blog/journal } \\
\text { assignment than I do when } \\
\text { writing an essay. }\end{array}$ & 33 & 22 & 22 & 9 & 6 \\
\hline 8. I enjoy writing. & 28 & 34 & 10 & 12 & 6 \\
\hline $\begin{array}{l}\text { 9. Once I got used to it, I found } \\
\text { the blog/journal tool } \\
\text { reasonably easy to use. }\end{array}$ & 42 & 31 & 10 & 5 & 3 \\
\hline $\begin{array}{l}\text { 10. I was able to make the } \\
\text { blog/journal look the way I } \\
\text { wanted it to look. }\end{array}$ & 28 & 32 & 11 & 14 & 5 \\
\hline $\begin{array}{l}\text { 11. Given the choice of writing } \\
\text { a } 2000 \text { word illustrated essay } \\
\text { or doing } 10 \times 200 \text { word } \\
\text { illustrated blog/journal } \\
\text { postings, I would choose to do } \\
\text { the } 2000 \text { word essay. }\end{array}$ & 11 & 14 & 22 & 24 & 20 \\
\hline $\begin{array}{l}\text { 12. I would be happy to } \\
\text { complete other written } \\
\text { assignments this way. }\end{array}$ & 40 & 33 & 8 & 5 & 6 \\
\hline $\begin{array}{l}\text { 13. I would recommend that } \\
\text { staff carry on using this type of } \\
\text { assignment in this module. }\end{array}$ & 49 & 22 & 13 & 3 & 4 \\
\hline $\begin{array}{l}\text { 14. It is very important to me } \\
\text { to have a good understanding } \\
\text { of the theory and history of my } \\
\text { subject. }\end{array}$ & 70 & 16 & 3 & 3 & o \\
\hline $\begin{array}{l}\text { 15. Being able to write well will } \\
\text { improve my chances of getting } \\
\text { a job when I graduate. }\end{array}$ & 54 & 27 & 9 & o & 2 \\
\hline
\end{tabular}




\begin{tabular}{|l|c|c|c|c|c|c|}
\hline & $\begin{array}{c}\text { A+, A } \\
\text { or A- }\end{array}$ & $\begin{array}{c}\text { B+, B } \\
\text { or B- }\end{array}$ & $\begin{array}{c}\text { C+, C } \\
\text { or C- }\end{array}$ & $\begin{array}{c}\mathrm{D}+, \mathrm{D} \\
\text { or D- }\end{array}$ & $\begin{array}{c}\mathrm{F}+, \mathrm{F} \\
\text { or F- }\end{array}$ & $\begin{array}{c}\text { Prefer } \\
\text { not to } \\
\text { say }\end{array}$ \\
\hline $\begin{array}{l}\text { 16. What grade did you get } \\
\text { for the assignment? }\end{array}$ & 11 & 53 & 21 & 5 & 0 & 2 \\
\hline
\end{tabular}

Table 4: Responses to grade question ( $n=92)$

\begin{tabular}{|l|c|c|c|c|c|}
\hline & $\begin{array}{c}\text { A lot } \\
\text { better }\end{array}$ & $\begin{array}{c}\text { A little } \\
\text { bit } \\
\text { better }\end{array}$ & $\begin{array}{c}\text { About } \\
\text { the } \\
\text { same }\end{array}$ & $\begin{array}{c}\text { A little } \\
\text { bit } \\
\text { worse }\end{array}$ & $\begin{array}{c}\text { A lot } \\
\text { worse }\end{array}$ \\
\hline $\begin{array}{l}\text { 17. Roughly speaking, do } \\
\text { you think that you did better } \\
\text { or worse in this assignment } \\
\text { than you normally do with } \\
\text { written assignments? }\end{array}$ & 15 & 17 & 44 & 13 & 1 \\
\hline
\end{tabular}

Table 5: Responses to perception of grade question $(n=90)$

An analysis of the grades given for the essay in the four years prior to adoption of the PTA (i.e. 2009/10 to 2012/13) as compared with grades for the PTA which replaced the essay in the four years $2013 / 14$ to $2016 / 17$ suggested that there was a difference in the awarding of marks between the essay and the PTA (see figure 1, below). A chi square test revealed a significance value of $\mathrm{p}=0.003$, confirming that the difference was statistically significant.

\section{Essay \& PTA Comparison$$
\text { Essay }(n=533) \square \text { PTA }(n=398)
$$

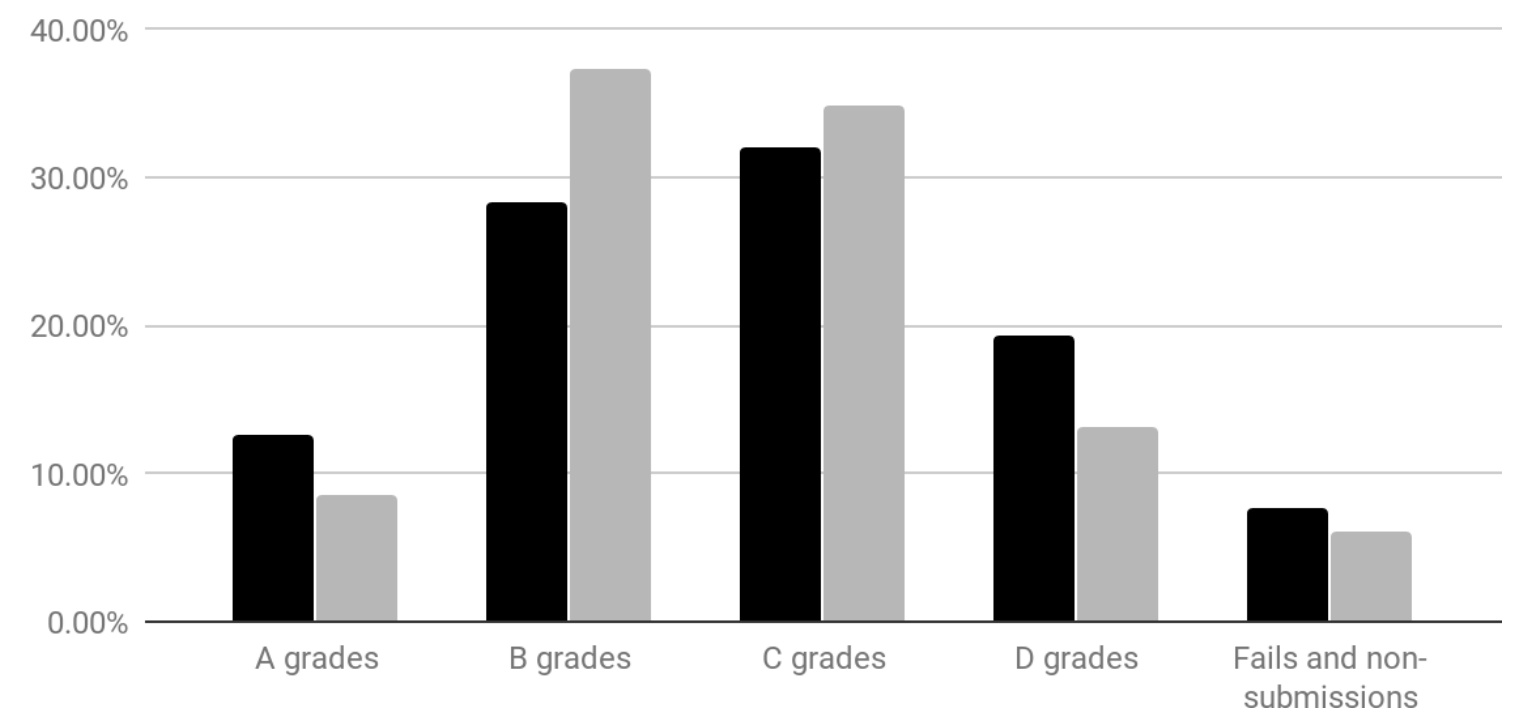

Figure 1: Distribution of grades for the essay (academic years 09/10 to 12/13) and PTA (academic years $13 / 14$ to $16 / 17)$ 


\subsection{Qualitative Findings}

A thematic analysis of the qualitative responses revealed five major themes, which were: (i) that students found the PTA challenging; (ii) that students enjoyed the PTA; (iii) that the PTA made the writing process more manageable; (iv) that the PTA helped students to improve their subject knowledge, and (v) that the PTA helped students to improve their study skills.

Of the sixty qualitative comments received from students, the largest set of comments (twenty in total) referred directly to difficulties or challenges with the PTA which were related either to the number of patches in the PTA or to keeping within the 250 word limit for the individual patches. Some students said that there were too many entries and suggested that there should be fewer entries, each with a longer word count limit. Some students simply noted that it was challenging to keep within the word limit, but without any suggestion that they felt negatively about this. A few students expressed a strong dislike to the limitations set by the PTA format, but others noted that although it was difficult to keep within the word limit, they felt positive about the requirement to be concise in their writing. Overall, while the theme of finding the PTA challenging was the largest single theme, it contained the full spectrum of responses, from students who said that the PTA "can be demanding, but it is not without its rewards" to students who "hated it because I felt I couldn't say enough on each topic."

The other major themes arising from the analysis of students' qualitative responses were all positive. The second largest theme contained eighteen comments from students who expressed highly positive feelings towards the PTA. At the extremely positive end of the spectrum, students referred to the PTA experience as being "delightful", "difficult ... but wonderful", "fantastic" and "brilliant". And the words 'enjoy' and 'enjoyed' cropped up multiple times in other responses. Some students enjoyed the PTA because it "relieves the pressure and stress of a huge essay" and because it comprises "short entries that are manageable".

The notion of manageability was common amongst students' responses, and twelve comments made a direct reference to this. For many students, writing the PTA was a positive experience simply because it spread out the writing workload in a way that was manageable. But the ways that students valued the manageability offered by the PTA varied. In their comments, students made reference to the PTA as relieving pressure, of stress levels going down, of being less intimidated or daunted by the writing tasks, the idea of "easy instalments", of getting down one's thoughts while they are still fresh, of managing time more efficiently, and being motivated to write continually during the course rather than leaving the writing to the last minute. All of these ideas contributed to the feeling that the structure imposed by the PTA was in general more helpful than it was restrictive. 
The fourth theme uncovered in students' comments was that the PTA helped them to improve their subject knowledge, and eleven students made comments to this effect. In these comments, students made it clear that it was the PTA format itself that was responsible for their learning more about the subject than they would otherwise have done (if the assessment item had been an essay, for example). Because students had to write on a variety of different subjects in the PTA, this meant that they had to read up on and learn about all of those subjects that they were writing about. Many of the students phrased these comments positively, and talked about the PTA as a "better learning process", of the "rewards" of the PTA, and of learning "in depth". On some occasions students referred to the way that the PTA "forced" them to learn more, but even these seemingly negative phrasings sat within comments which indicated that they were appreciative of the learning experience 'forced' on them by the PTA.

The final theme related to students' study skills, and eight of the comments refer to this. The notion of improved study skills had two main aspects to it. The first was concerned with students learning to be more precise, and here students talked about having to avoid "waffle", and about "focus" and being "concise" in both their thinking and their writing. The second aspect was about the way that the PTA encouraged students to make studying a regular habit, rather than something that is done only in the days immediately before an assessment is due. These students talked about the PTA increasing the frequency and regularity of their studies - they read more books and journals and wrote and more often and more regularly. If anything, this reflects the fact that the PTA provided the students with a more realistic experience of, and insight into, the activity of writing about art that is premised on the need for it to be an iterative form of practice wherein an argument, position or set of critically informed responses are incrementally established, rather than immediately arrived at.

\section{Discussion}

Taken together, the findings presented above suggest that replacing the essay with the PTA was successful not in spite of the difficulties that the format presented to students, but precisely because of those difficulties. The quantitative responses presented in table 3 (above) show that students' feelings towards the PTA were broadly positive, and this is especially true in respect of the most important PTA questions (i.e., Q1, Q2, Q3 and Q13). One of the most interesting findings is the change in grade distribution between the essay and the PTA (figure 1). This showed that there were fewer D grades, and fewer fails and non-submissions with the PTA than with the essay. This suggests that lower-achieving students were better supported by the PTA and were less likely to fail and more likely to submit work for assessment. Figure 1 also shows that more students received $\mathrm{B}$ grades than $\mathrm{C}$ grades for the PTA, with the mode grade changing from $\mathrm{C}$ with the essay, to $\mathrm{B}$ with the PTA. But as is also clear, lower grades going up is only part of the reason for these 
changes; the other reason being that fewer students received A grades in the PTA than in the essay. This suggests that while the PTA may better support lowerachieving students, higher-achieving students may find it more difficult to distinguish themselves in a PTA. However, why this should be the case is not clear. The absence of a control group means that one might question whether the students in the essay and PTA groups were of similar abilities, and while the fact that both groups comprised several hundred students and were measured over four years each helps to minimise such possible variations between the groups, this question cannot be entirely discounted. What this finding does suggest is that future research into PTA might look at the question of whether changing from an essay to a PTA affects all students equally.

The fact that the majority of qualitative comments focused on the challenges presented by the PTA format was encouraging because it countered the suggestion that improvements in student grades at the lower end were due to adopting an easier form of assessment. In one respect, the challenges came from the fact that there was a greater onus on students being able to identify and form appropriate connections between what they think is relevant information. This would be between aspects derived from a particular taught session, relevant supporting research and their own critical responses to the topic at hand. It is perhaps not simply a question of the challenge being bound up with having to research more things (although this might be a contributing factor); rather, the format of the written assignment is such that it is premised on the need to consistently make judicious and informed choices in a way that is arguably more pro-active or 'hands-on.' Moreover, one could argue that this works against the possibility that academic depth necessarily has to be relinquished. To this end, a particular topic at hand still has to be dealt with critically and supported with appropriate levels of scholarly research. It is perhaps worth noting that the PTA formed one element of assessment for level 4 and level 5 learners. Within their Major Critical Study, a 40-credit module, Level 6 students had the opportunity to identify a particular topic and approach it in greater depth and in a more sustained way than the patchwork text assignments. In order to bridge the transition between the learner's experiences of working with the PTA at level 4 and the demands of their Major Critical Study at Level 6, for level five learners the assessment items for their 'theory' module encompassed approaches that could be construed as being arguably more in-depth, either due to prescribed word count, e.g., a 2000 word essay or by the requirement of having to focus on an identified topic, as in the case of a verbal presentation.

It is important to note that the difference in the pre- and post-PTA grades did not come from a change in staff, because the module tutor (the lead author of this paper) was the same person from the beginning of the 2009/10 academic year though to the end of the 2016/17 academic year. The responses to Q17 were also encouraging in this respect, as they show only a small shift towards students perceiving that they did better with the PTA than is usual with their written assignment. Had the perceived 
shift been larger this might have suggested that the PTA was seen as a soft(er) option but fortunately this was not the case. Precisely how the survey respondents came to make their decisions when answering Q17 is not clear. While it is likely that secondyear students were comparing their experience of the PTA with their experiences of writing essays in their first year of study, it may have been the case that first-year students were comparing their PTA experience with their experiences of writing essays at school. Here it would have been useful to have run focus groups in order to have had the opportunity to delve deeper into this topic. Nevertheless, taking all of the students' comments holistically, there is a strong sense of there being nowhere to hide within a PTA. Some students clearly saw that the PTA was a greater challenge than an essay, because they had to understand a greater range of topics, and then had to strip each topic back to its essentials in order to write within the word limit for each patch.

Anecdotally, level 4 students often declared their ambivalence towards writing generally, something which was often related to experiences during their secondary education. This could in part be due to the fact that when Fine Art students arrive at university they bring with them an assumption that they are there to 'make' rather than to write. The reasons for this are indeed manifold, but as Kill (2006) points out, this is something that has been "reinforced in much of the literature produced about, and in support of, undergraduate art and design education during the last few decades" (Kill, 2006: 310). To a certain extent, I would imagine that when students did self-report, this would have been in relation to their previous experiences of undertaking written assignments at school. On one level, the reason that the patchwork text method was adopted was due to the fact that it provided a more accessible means by which the practice of writing and by extension, following Lockheart (2018: 171), the idea of writing as practice, with "its words and images as emergent material," could be approached, undertaken and hopefully meaningfully claimed by the individual learner. Part of the task was to encourage the learners to claim ownership of writing in a way that they slowly claim ownership of their creative practice. To this end, the more 'bite-size' approach of the patchwork text deliberately mirrored the project-based structure that Fine Art students experience in their first year, a structure that enables them to test out a number of different possibilities, approaches and ideas. Both were put in place so as to not overwhelm the learner but to encourage a critical and meaningful purchase with the task at hand. However, it's perhaps important to note that the level six students' responses as set out here would also be given in relation to another submission they would have been required to engage with during their first year at university. Following the PTA, the second assessment item was a 1500-word essay that required the learner to visually analyse a work of art first hand.

From the perspective of the modules' delivery, what the PTA encouraged was arguably a more pointed and focused engagement with the respective topics, themes, issues and ideas that contributed to or formed the basis of a particular patch. The 
frequency and regularity of their studies that students observed and that was highlighted in the survey findings in one sense worked to emphasise the practical nature of writing and, by extension, the idea that it could be construed as practice. As well as foregrounding a more realistic approach to both understanding and actually engaging in the process of writing, there were now the conditions of possibility for the 'practice' of writing to be seen as being, to a certain extent comparable to the studio practice. Both are processes that require self-reflection, criticality, diligence and approach the task at hand iteratively, as an incremental development of ideas, positions and responses to a delimited set of issues or thematics.

\section{Limitations}

The main limitation of this study is that the survey respondents are not wholly representative of the survey population. As can be seen from table 6 (below), the grades as self-reported by the students indicate that the survey was taken by an unrepresentative group of students, in that the survey respondents comprised a higher percentage of higher achieving students. Almost seventy percent of students responding to the survey self-reported receiving an A or B grade, whereas only fortyfive percent of grades awarded for the PTA assignment were A or B grades. Therefore, it should be borne in mind that it may be the case that the findings of this research project present a slightly more positive picture of PTA than is actually the case.

\begin{tabular}{|l|c|c|c|c|c|c|}
\hline & $\begin{array}{c}\mathrm{A}+, \mathrm{A} \\
\text { or A- }\end{array}$ & $\begin{array}{c}\mathrm{B}+, \mathrm{B} \text { or } \\
\mathrm{B}-\end{array}$ & $\begin{array}{c}\mathrm{C}+, \mathrm{C} \text { or } \\
\mathrm{C}-\end{array}$ & $\begin{array}{c}\mathrm{D}+, \mathrm{D} \\
\text { or D- }\end{array}$ & $\begin{array}{c}\text { F+, F or } \\
\text { F- }\end{array}$ & $\begin{array}{c}\text { Prefer } \\
\text { not to } \\
\text { say }\end{array}$ \\
\hline $\begin{array}{l}\text { Grades as self-reported by } \\
\text { survey respondents (n=92) }\end{array}$ & $\begin{array}{c}11 \\
(12 \%)\end{array}$ & $\begin{array}{c}53 \\
(57.6 \%)\end{array}$ & $\begin{array}{c}21 \\
(22.8 \%)\end{array}$ & $\begin{array}{c}5 \\
(5.4 \%)\end{array}$ & 0 & $\begin{array}{c}2 \\
(2.2 \%)\end{array}$ \\
\hline $\begin{array}{l}\text { Actual grades awarded } \\
(\mathrm{n}=398)\end{array}$ & $\begin{array}{c}34 \\
(8.5 \%)\end{array}$ & $\begin{array}{c}149 \\
(37.4 \%)\end{array}$ & $\begin{array}{c}139 \\
(34.9 \%)\end{array}$ & $\begin{array}{c}52 \\
(13.1 \%)\end{array}$ & $\begin{array}{c}24 \\
(6 \%)\end{array}$ & $\mathrm{n} / \mathrm{a}$ \\
\hline
\end{tabular}

Table 6: Self-reported grades compared to actually awarded grades

\section{Conclusion}

The main conclusion from this study is that, for the most part, students found completing a PTA more difficult, more enjoyable, and more rewarding than writing an essay. Importantly, there was no suggestion that the PTA contributed to a dumbing down of assessment practices via an excessive change in emphasis from depth to breadth of knowledge. And neither did the change lead to an increase in the workload of the academic staff supporting and assessing the PTA over what would normally be expected when supporting and assessing an essay. With regard to this, the patchwork text assignment didn't substantively increase the module tutor's workload. Formative assessment consisted of providing written and verbal feedback 
based on a sample 'patch' of text and once the assignment had been submitted the marked assignment was returned to the student and accompanied by a piece of written feedback which summarised the salient aspects of the assignment. To this end, the level or extent of written and verbal feedback required was directly comparable to what would have been required from a more orthodox essay comprised of a single topic or area of focus.

The five key findings from this study are that:

- students found the PTA challenging;

- students enjoyed the PTA;

- the PTA made the writing process more manageable;

- the PTA helped students to improve their subject knowledge;

- the PTA helped students to improve their study skills.

In the study, the PTA required students to write more regularly and to engage with a wider range of topics than would have been the case when writing an essay. It developed students' abilities to write in a focused way, and, because the patches were closely aligned to the teaching schedule, strongly encouraged and rewarded attendance at taught sessions. It also gave academic staff a more immediate impression about which students needed additional support with their writing, and this allowed for early recommendations to contact academic support staff (e.g., learning development tutors, academic librarians, etc.) or to make appointments with their personal academic tutors for support.

The subject of depth versus breadth of knowledge is important to consider, and should not go unacknowledged. While it might be imagined that the PTA simply divides up a fixed or predetermined amount of reading, research and writing into as many patches as are required, this does not appear to be the case. Clearly it is highly unlikely that students put as much work into one patch as they do into a whole essay, but, as academics know, students' study time is somewhat elastic, and if there are eight patches, for example, the work that goes into each patch does not appear to be one-eighth the work of an essay. Our experience suggests that because the PTA keeps students reading, researching and writing at regular intervals, it is the case that more work goes into a PTA than into an essay of the same length. Of course, this is based to some extent on intuition and anecdotal experience, but can also be extrapolated in part from students' qualitative comments, although ultimately would need to be confirmed by further research. Nevertheless, it does need to be acknowledged that when discussing any perceived trade-off between depth and breadth of knowledge when comparing essays and PTAs one risks privileging quantity of work rather than quality of work. If we take the term 'depth' to mean 'of a higher or better quality' (rather than simply 'more'), then whether students write 2,000 or 250 words on a particular topic in no way guarantees anything about the quality of work they produce. Whether an essay or a PTA is more likely to encourage higher quality responses is currently a moot point. For example, does the fact that students have to 
write the final, reflexive meta-patch in a PTA make it more likely that students will at least have to evidence relational thinking, the penultimate stage of the SOLO taxonomy? Or is there something inherent in the essay which drives students towards the final, extended abstract stage of the SOLO taxonomy (Biggs and Collis, 1982, passim; Biggs and Tang, 2011, passim). Presumably quality of responses has as much to do with the way that assessments are deployed in the context of a carefully designed programme of studies and well-thought-out assessment strategy, and the extent to which students are supported with the assessment, as it does with the inherent virtue of any particular assessment method.

Obviously, there is no recommendation that all essays should be replaced by PTAs; rather the suggestion is that the two are complementary, because the PTA can engage, motivate and reward students differently and in ways that the essay cannot. Provided that students still have opportunities to write essays elsewhere in their course (and participate in other forms of assessment as well) there seems to be little risk in changing one or two essays to PTA, especially at levels four and five. The essay is, of course, likely to remain a staple of higher education assessment practices indefinitely, as its strengths are numerous and so well-rehearsed that there is little point in enumerating them here. But the essay has weaknesses too. Aside from those noted by Winter (see section 2, above), while academics and other experienced essay writers know the need to keep their writing succinct and to-the-point and may find 1,500 to 2,000 words a very low word count, to first and second-year undergraduates this may seem like a very high word count indeed, and one which is likely to be achieved only with the judicious use of some 'padding' or waffle. The low word count of the PTA entries focuses students on the need for brevity and precision right from the start, and while this could benefit their future essay writing practice, it could have other benefits too. Being able to write concise and focused prose is an important and valuable transferable skill for students to develop, and when composing tweets, emails, blog posts or when using any one of the myriad communication formats available in today's technology rich but time-poor world, communicating concisely without over-simplification is key. Giving students the opportunity to practice this skill in a formal setting, alongside other assessment formats which allow them to complete extended writing tasks, is what the PTA does particularly well.

When comparing essays to PTAs one might even go so far as to argue that the PTA is more in keeping with the original spirit of the essay than is the modern essay. As Winter (2003b) points out, the essay unfairly puts students into the position of subject matters experts inasmuch as it requires them to offer up an authoritative position about the subject in question. As well as arguing that this is an unrealistic expectation to have of students, especially first and second year undergraduates, it is perhaps helpful to remember that this was not even the original intention of the essay. Essay, from the French essai, meaning a trial, test, or attempt, was often a much looser and more exploratory form than we currently allow, especially if one 
takes Montaigne as the model of the original essayist. As Sarah Bakewell notes in her study of Montaigne,

Having created a new genre ... Montaigne created essais: his new term for it. Today the word 'essay' falls with a thud. It reminds many people of the exercises imposed at school or college to test knowledge of the reading list: reworkings of other writers' arguments with a boring introduction and a facile conclusion stuck into each end like two forks in a corn cob. Discourses of that sort existed in Montaigne's day, but essais did not. Essayer, in French, means simply to try. To essay something is to test or taste it, or give it a whirl (Bakewell 2010: 7-8).

Perhaps then, by adopting the PTA as an assessment instrument, we might then get back to the original intention of the essay. Freed from the need to falsely claim authority and expertise over areas of study into which they have only just begun to explore, the PTA can allow students more leeway and liberty to try out ideas, to test hunches and to take risks without being reprimanded for failure. Mirroring Paul Klee's famous phrase that drawing is the process of taking a line for a walk, the PTA, like one of Montaigne's essais, can be thought of as a format which encourages students to take a series of ideas on a journey.

\section{References}

Bakewell, S. (2010) How to Live: A Life of Montaigne in one question and twenty attempts at an answer. London: Chatto \& Windus.

BERA (2011) Ethical Guidelines for Educational Research. London: BERA.

Biggs, J. and Collis, K. (1982) Evaluating the Quality of Learning: The SOLO Taxonomy. London: Academic Press.

Biggs, J. and Tang, C. (2011) Teaching for Quality Learning in Higher Education, 4th Edition. Maidenhead: Society for Research into Higher Education \& Open University Press.

Borg, E. (2012) Writing differently in Art and Design: Innovative approaches to writing tasks. In: Clughen, L. and Hardy, C. (eds.) Writing in the Disciplines, Building Supportive Cultures for Student Writing in UK Higher Education. Bingly: Emerald Group Publishing Limited, pp.169-186.

Kill, R. (2006) Coming in From the Cold: Imperialist Legacies and Tactical Criticalities. JADE 25(3), pp.308-317.

Lillis, T. (2001) Student Writing: Access, Regulation, Desire. London: Routledge. 
Lockheart, J. (2018), 'The importance of writing as a material practice for art and design students: A contemporary rereading of the Coldstream Reports', Art, Design \& Communication in Higher Education, 17:2, pp. 151-75, doi: 10.1386/adch.17.2.151_1

Lockheart, J., Edwards, H., Raein, M., and Raatz, C. (2004), 'Writing Purposefully in Art and Design (Writing PAD)', Art, Design \& Communication in Higher Education 3(2), pp.89-102. DOI: 10.1386/adch.3.2.89/o

Marcangelo, C. (2011) JISC Final Report - Digitally-enhanced Patchwork Text Assessment. JISC Digital Enhanced Patchwork Text Assessment Project (DePTA) [online]. Available from: https://dpta.files.wordpress.com/2012/o1/microsoft-worddepta-final-report-2nd-aug-11.pdf

Mayfield, W. (2005) The Student Experience - a response to Designers are Writers. WritingPAD [online], Available from: http://www.writing-pad.ac.uk.

Wilson, G. (2012) Is academic writing the most appropriate complement to art students' practice? The Open University: Doctorate in Education. Available from: http://oro.open.ac.uk/54523/

Winter, R. (2003a) 'Surface Learning': The Patchwork Text as a Remedy for the Academic Essay (A slightly amended version of an article published in The Guardian, Education Section, Tuesday June 10th, 2003, p.15). Richard Winter [online]. Available from:

http://www.richardwinter.net/sites/richardwinter/files/Patchwork\%2oText\%20Gua rdian\%20Article.pdf

Winter, R. (2003b) Contextualising the Patchwork Text. In: Winter, R., Parker, J. and Ovens, P. (eds.) The Patchwork Text: A Radical Re-Assessment of Coursework Assignments - A Special Issue of Innovations in Education and Teaching International. Innovations in Education and Teaching International, 40(2), pp.112122. DOI: $10.1080 / 1470329031000088978$ 